\title{
The hydrogenation of the series of methylene-interrupted cis,cis-octadecadienoic acids by pure cultures of six rumen bacteria
}

\author{
BY PATRICK KEMP AND DAVID J. LANDER \\ AFRC Institute of Animal Physiology, Babraham, Cambridge CB2 4AT \\ AND R. T. HOLMAN \\ The Hormel Institute, University of Minnesota, Austin, Minnesota 55912, USA
}

(Received 27 January 1984 - Accepted 26 February 1984)

1. The hydrogenation of all the methylene-interrupted cis,cis-octadecadienoic acids was examined using pure cultures of six rumen bacteria able to hydrogenate linoleic acid to stearic acid or its immediate precursor, trans-11-octadecenoic acid, after first conjugating the linoleic acid to cis,trans-9,11-octadecadienoic acid.

2. Only the $\Delta 14-c i s, 17-c i s$-isomer was not hydrogenated by at least one of the bacteria and no evidence was found that conjugation was necessary before hydrogenation except for the $\Delta 2$-cis,5-cis- and $\Delta 9-c i s, 12-c i s-i s o m e r s$. Several isomers were hydrogenated to an extent close to that achieved with linoleic acid ( $\Delta 9-c i s, 12-c i s)$.

3. Those bacteria only able to hydrogenate linoleic to trans-11-octadecenoic acid gave only octadecenoic acid products and those bacteria able to hydrogenate linoleic acid to stearic gave variable yields of octadecenoic acids and stearic acid except with the isomers $\Delta 12$-cis, 15-cis and $\Delta 13$-cis, 16-cis when only octadecenoic acids were detected.

4. At the substrate levels used $(20 \mu \mathrm{g} / \mathrm{ml})$, both inhibition and stimulation of growth were found but no common pattern emerged, nor was the growth consistently related to the extent of hydrogenation.

In the rumen, free linoleic acid (cis,cis-9,12-octadecadienoic acid), resulting from microbial hydrolysis of complex dietary lipids, is rapidly hydrogenated by bacteria to stearic acid (Dawson \& Kemp, 1970). The intermediates in the sequence of hydrogenation steps from linoleic acid to stearic acid have all been well characterized using mixed rumen microorganisms in vitro (Dawson \& Kemp, 1970) and with pure cultures of rumen bacteria (Kemp et al. 1975). In all the systems so far examined, before hydrogenation of linoleic acid may proceed, the isomerization of the $\Delta 9$-cis,12-cis double bond system to the conjugated $\Delta 9$-cis, $\Delta 11$-trans is a necessary step. The enzyme responsible for this conjugation, linoleate $\Delta 12$-cis, $\Delta 1$ 1-trans isomerase (EC 5.2.1.5), was isolated by Kepler \& Tove (1967) from a Butyrivibrio fibrisolvens; it was shown to be specific for the $\Delta 9$-cis,12-cis diene system and required a free carboxylic acid group (Kepler et al. 1971) for activity. Garcia et al. (1976) examined all the cis,cis-methylene-interrupted octadecadienoic acids and found that the $\Delta 2,5$-isomer was also a substrate for the isomerase and that whole cells of Butyrivibrio fibrisolvens slowly hydrogenated the conjugated product to monoenoic acid.

The intermediates in the hydrogenation of $\alpha$-linolenic acid (Kemp et al. 1975) and $\gamma$-linolenic acid (Kemp \& Lander, 1983), trans,cis-11,15-octadecadienoic acid and cis,trans6,11-octadecadienoic acid respectively, and the cis,cis-5,9-octadecadienoic acid found in yew (Taxus baccata) seeds (P. Kemp, unpublished results) are all hydrogenated to stearic acid. Since we knew a wide range of $c i s$ - and trans-octadecenoic acids were hydrogenated (Kemp et al. 1979) we decided to use six pure strains of rumen bacteria to examine the hydrogenation of the series of cis,cis-methylene-interrupted octadecadienoic acids. These bacteria fall into two groups on the basis of their hydrogenation of linoleic acid (Kemp \& Lander, 1984). Group A can hydrogenate linoleic acid only to trans-11-octadecenoic acid, but group B can hydrogenate linoleic acid to stearic acid. The Butyrivibrio fibrisolvens used by Kepler \& Tove (1967) would be included in group A. 
In the present paper we report that, with the exception of the $\Delta 14,17$-isomer, the whole series of $c i s, c i s$-octadecadienoic acids are hydrogenated and only the $\Delta 2,5$ - and $\Delta 9,12$-isomers require previous conjugation.

\section{MATERIALS AND METHODS}

Reagents were of analytical grade when available. The series of $c i s$,cis-methylene-interrupted octadecadienoic acids (Christie \& Holman, 1967) were stored under nitrogen at $-70^{\circ}$.

Culture of bacteria. Group A: LM 8/1 B, gram - ve rod; EC7/2, gram - ve rod (Hazlewood et al. 1976) and S2, Butyrivibrio sp. (Hazlewood \& Dawson, 1975, 1979); group B: P2/2, Fusocillus babrahamensis NCIB 10838; T344, Fusocillus sp. NCIB 11026 (Kemp et al. 1975 ) and R 8/5, gram - ve rod were subcultured monthly and maintained on agar slopes $(20 \mathrm{~g} / \mathrm{l})$ stored at $4^{\circ}$ or in liquid media stored at $-70^{\circ}$. The culture medium, low in 18-carbon fatty acids, contained ( $\mathrm{g} / \mathrm{l}$ in the complete medium): Bactocasitone (Difco) 10, yeast extract (Difco) 2.5, $\mathrm{KH}_{2} \mathrm{PO}_{4} 0.45, \mathrm{~K}_{2} \mathrm{HPO}_{4} 0.45, \mathrm{NaCl} 0.9,\left(\mathrm{NH}_{4}\right)_{2} \mathrm{SO}_{4} 0.9, \mathrm{MgSO}_{4} .7 \mathrm{H}_{2} \mathrm{O} 0.09$, $\mathrm{CaCl}_{2} \cdot 2 \mathrm{H}_{2} \mathrm{O} 0 \cdot 12$, resazurin $0 \cdot 01$, soluble starch $1 \cdot 0$. The medium used for the growth of $\mathrm{S} 2$ was fortified with palmitic acid $(0.01 \mathrm{~g} / 1)$ and that for $\mathrm{P} 2 / 2$ with decoic acid $(0.01 \mathrm{~g} / 1)$. These fatty acids dissolved in methanol were added to the medium before autoclaving $\left(6.9 \mathrm{kPa}(10 \mathrm{psi})\right.$ at $115^{\circ}$ for $\left.20 \mathrm{~min}\right)$. The reducing solution, sterilized by filtration, contained ( $\mathrm{g} / \mathrm{l}$ in the complete medium): glucose $0 \cdot 5$, cellobiose $0 \cdot 5$, cysteine hydrochloride $1 \cdot 0, \mathrm{NaHCO}_{3} 8 \cdot 0$. The complete medium, when equilibrated with oxygen-free carbon dioxide, had a $\mathrm{pH}$ of 6.8 and was prepared and inoculated by the open-tube method (Hungate, 1969; Latham \& Sharpe, 1971). Incubations were at $39^{\circ}$ and growth was assessed by measuring the optical density using an EEL colorimeter (Evans Electroselenium Ltd, Harlow, Essex), ORI filter and a $13 \mathrm{~mm}$ light path.

Preparation of media containing substrate. Octadecadienoic acid isomer $(200 \mu \mathrm{g})$ dissolved in methanol $(20 \mu \mathrm{l})$ was added to $0.5 \mathrm{ml}$ unreduced medium and the tube plugged with cotton wool and sterilized. Whilst hot, $9.5 \mathrm{ml}$ of the reduced medium was added and the tube closed with a butyl-rubber bung.

Analysis of hydrogenation products. The extraction of the total lipid from the cultures, the preparation of fatty acid methyl esters and their analysis by gas-liquid chromatography (GLC) and argentation thin-layer chromatography (TLC) was essentially as described by Kemp et al. (1975). Peak areas of components in GLC analyses were quantified using a Hewlett Packard $3380 \mathrm{~A}$ integrator. Heptadecanoic acid was added to the extraction mixture as an internal standard.

\section{RESULTS}

Media containing octadecadienoic acid substrates were inoculated with a portion (20 ml/1) of a fresh culture (grown for $18 \mathrm{~h}$ in the basal medium) and grown for $20 \mathrm{~h}$. Growth was assessed at intervals by measuring the optical density of the cultures. For each experimental point the mean value from three to four tubes was used for the initial experiment and two to three tubes for repetitions. By $12-15 \mathrm{~h}$ incubation there was little difference between the growth of the bacteria in the media containing octadecadienoic acid isomers and controls. Between 15 and $20 \mathrm{~h}$, differences became apparent, the largest deviation being $28 \%$ from the control. Maximal optical density for all six bacterial cultures was found at $18-20 \mathrm{~h}$. The optical densities at $20 \mathrm{~h}$ for the six bacteria with each isomer and the control medium are shown in Fig. 1. Repetitions gave similar relative values to those recorded. In general, growth in media containing isomers with double bonds nearer the carboxyl group than $\Delta 9,12$ was, with the exception of $\mathrm{R} 8 / 5$, lower than in the control media, indicating some 


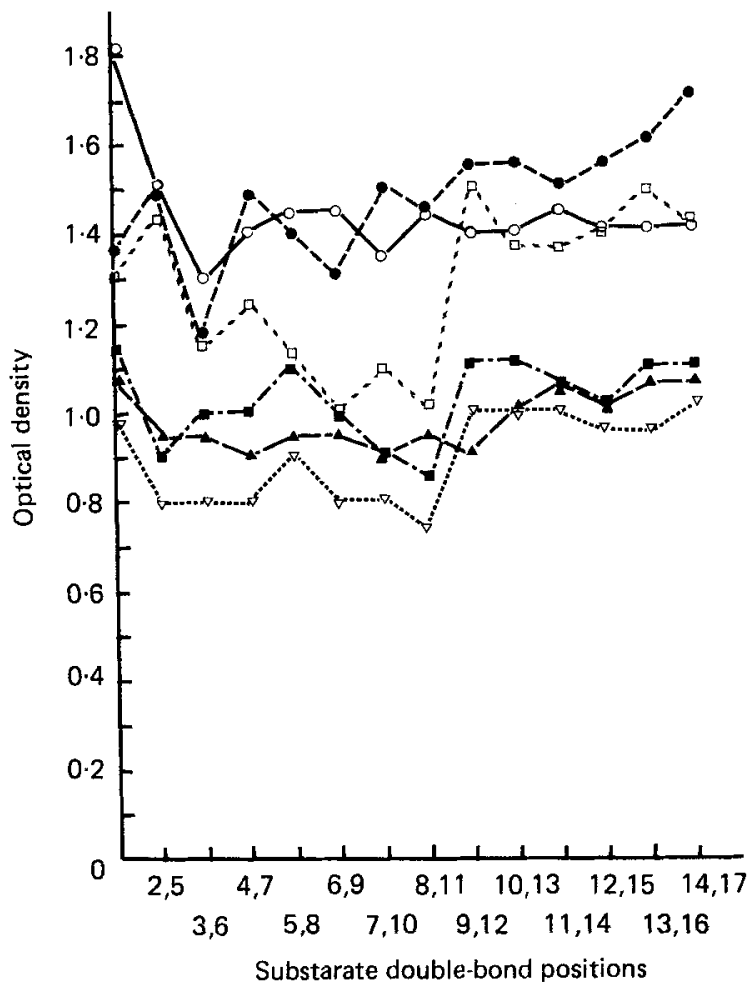

Fig. 1. Growth of bacteria in the basal and cis,cis-octadecadienoic acid-supplemented media. Growth (optical density) of LM 8/1 B (O), R 8/5 (O), EC 7/2 ( $\square$ ), T $344(\square)$, S 2 ( $\nabla)$ and P 2/2 (A). The basal medium and media supplemented $(20 \mu \mathrm{g} / \mathrm{ml})$ with individual octadecadienoic acid isomers were inoculated with a portion $(20 \mathrm{ml} / \mathrm{l})$ of a young culture and incubated for $20 \mathrm{~h}$ at $39^{\circ}$.

inhibition. In media containing isomers with double-bond positions towards the methyl end of the paraffin chain $(\Delta 9,12-\Delta 14,17)$ there was a change back to control values of growth and in two isolates, $\mathrm{R} 8 / 5$ and $\mathrm{EC} 7 / 2$, a small stimulation of growth was found. The change from inhibition towards control values at the mid-point of the chain $(\Delta 9,12)$ was most noticeable with bacterium EC 7/2 (Fig. 1). Bacterium P2/2 was least affected and bacterium LM 8/1 B was uniformly inhibited (17-28\% below control value) by octadecadienoic acids in the media.

Hydrogenation of octadecadienoic acid isomers. The fatty acids from the tubes in the growth experiment were extracted and their methyl esters examined by GLC for hydrogenation products. Recoveries of unchanged substrate and products were in the range $85-90 \%$ of the substrate used. No conjugated diene was detected in any sample and the only products were octadecenoic acids and stearic acid. None of the group A bacteria (S 2, LM8/1 B and EC7/2; Fig. 2) hydrogenated the $\Delta 4,7-; \Delta 5,8-; \Delta 6,9-; \Delta 13,16-$ or $\Delta 14,17-$ isomers, only EC7/2 hydrogenated the $\Delta 8,11$-isomer $(57 \%$ ) and only LM $8 / 1$ B hydrogenated the $\Delta 7,10$-isomer $(4 \%)$. No stearic acid was detected in the hydrogenation products of the group A bacteria. The substrate specificity and hydrogenation yields for S2 and EC7/2 showed broad similarity except for the $\Delta 8,11$-isomer. LM8/1 B hydrogenated only three isomers: $\Delta 7,10 ; \Delta 9,12$ and $\Delta 10,13$.

The group B bacteria hydrogenated a wider range of isomers than the group A bacteria and the results were more complicated by the initial octadecenoic acids products, which were 


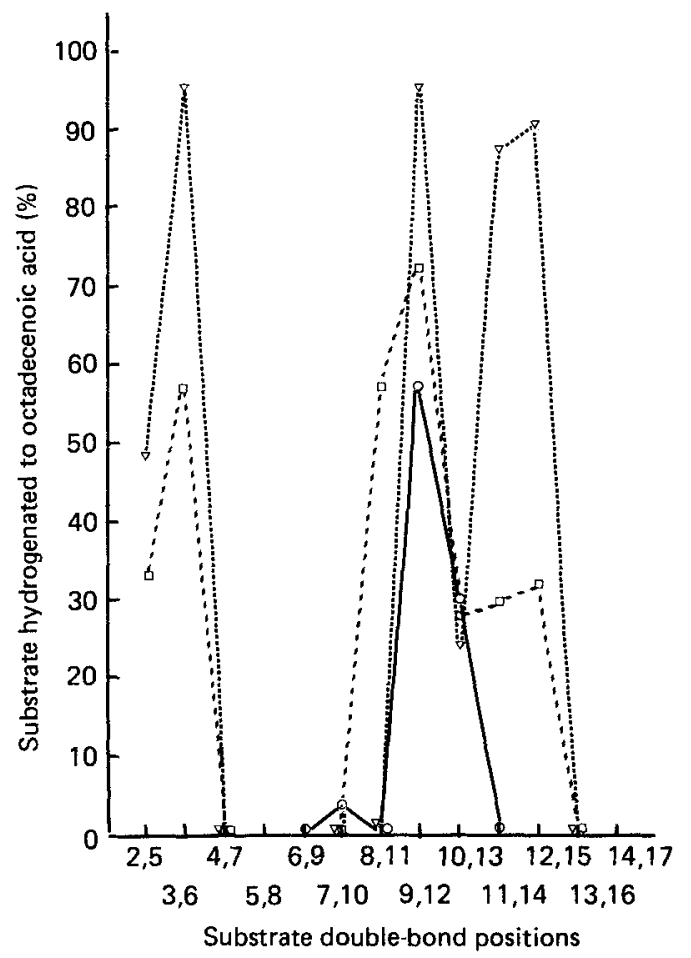

Fig. 2. Yields of hydrogenated products of bacteria S2, EC7/2 and LM8/1 B. Yield of octadecenoic acid methyl esters is given as the percentage of the total octadecanoic acid products and octadecadienoic acid substrate methyl esters (on a weight basis) eluted from a gas-liquid chromatographic column when bacteria S2 $(\nabla)$, EC 7/2 ( $\square)$ or LM 8/1 B (O) were grown from inocula $(20 \mathrm{ml} / \mathrm{l})$ for $20 \mathrm{~h}$ at $39^{\circ}$ in media containing $20 \mu \mathrm{g} / \mathrm{ml}$ of individual methylene-interrupted cis,cis-octadecadienoic acid isomers.

in most instances hydrogenated further in good yield to stearic acid. The results are shown in Fig. $3 a-c$, for $\mathrm{P} 2 / 2, \mathrm{~T} 344$ and $\mathrm{R} 8 / 5$ respectively. The $\Delta 14,17$-isomer was not hydrogenated by group B bacteria and the $\Delta 13,16$-isomer was hydrogenated only by bacterium $T 344$ and only to octadecenoic acid. Bacteria $T 344$ and $P 2 / 2$ hydrogenated the $\Delta 12,15$-isomer to octadecenoic acid. Bacteria T 344 and P2/2 hydrogenated the rest of the isomers to octadecenvic acid and stearic acid. Bacterium $\mathrm{R} 8 / 5$ showed less preference for individual isomers than either $\mathrm{P} 2 / 2$ or $\mathrm{T} 344$ but showed poor conversions of octadecenoic acid to stearic acid, in spite of $\mathrm{R} 8 / 5$ giving the highest growth yields (Fig. 1).

The octadecenoic acid produced from linoleic acid $(\Delta 9,12$-isomer) by all six bacteria was predominantly the trans-11-isomer, but there was evidence from GLC and TLC indicating positional isomerization especially with bacteria P2/2 and T344. Positional and possible geometric isomerization was also evident in the products from isomers $\Delta 10,13$ and $\Delta 11,14$ grown with bacteria P2/2 and T344, although there appeared, from GLC results, to be non-specific hydrogenation of the double bonds of these two isomers.

The differences in growth yield did not show any general overall correlation with differences in hydrogenation except for the $\Delta 9,12$-isomer. Bacteria S2, T 344 and EC7/2 all grew poorly with the $\Delta 8,11$-isomer, but whilst $\mathrm{T} 344$ and $\mathrm{S} 2$ gave $4 \%$ and no hydrogenation respectively, EC7/2 gave a $57 \%$ yield of octadecenoic acid.

To check if variable growth might be a contributing factor to some of the differences in hydrogenation rates between isomers, cultures of each bacterium were grown from a $2 \%$ inoculation for $20 \mathrm{~h}$ and then added to the individual isomers suspended in a small volume 


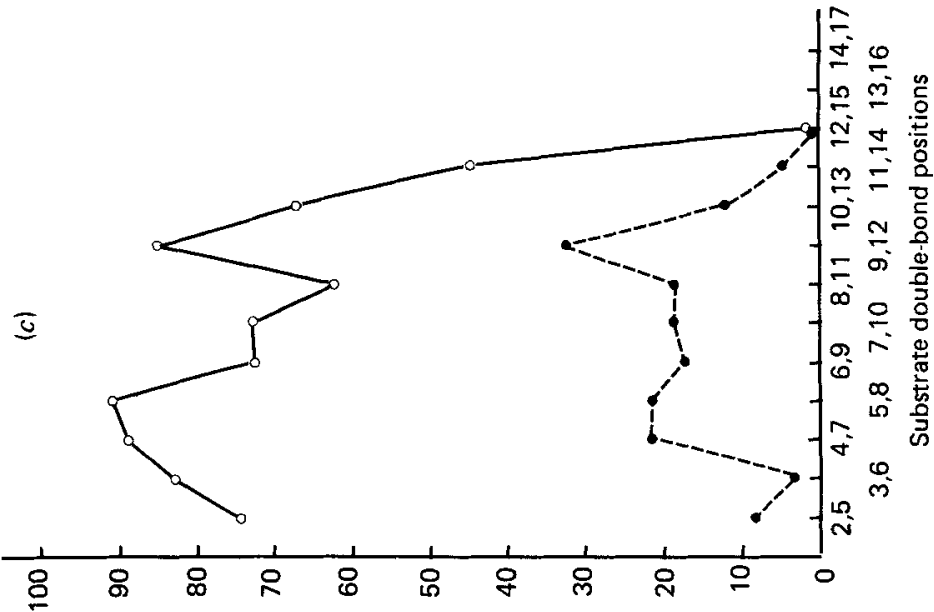

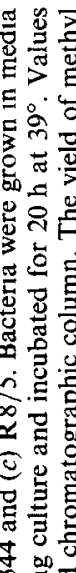

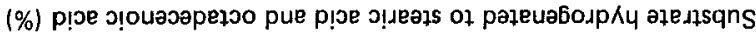

总?

a…

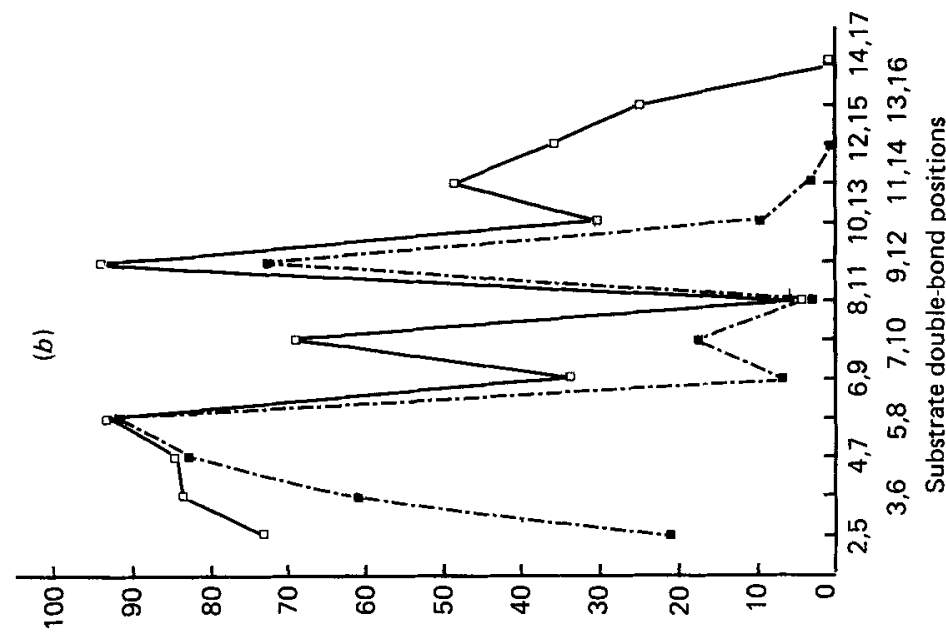

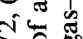

sิ

จे हี

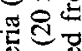

焉

0.0

范

比

悹

政

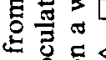

氜

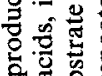

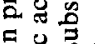

a

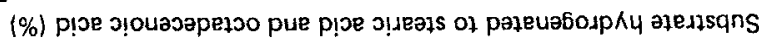

焉总

㩆总

密

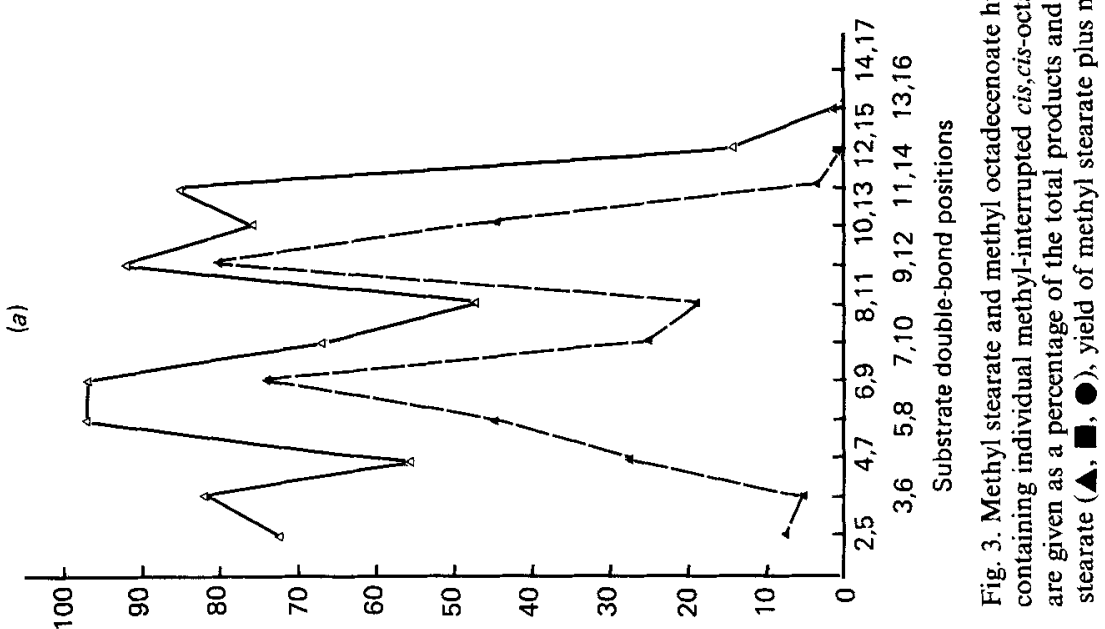

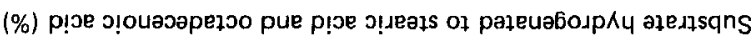


of sterile but unreduced medium. The cultures plus substrate were incubated for a further $4 \mathrm{~h}$, during which time there was no increase in optical density. The results were essentially the same as were found when the cultures were grown in the presence of the isomers. Single tubes were examined for products at 5 min after mixing; all bacteria produced up to $5 \%$ conjugated diene with the $\Delta 9,12$-isomer and a product with a longer retention time (GLC) than the substrate in incubations containing the $\Delta 2,5$-isomer. The product was not positively identified as a conjugated diene. With the other isomers we found only low levels of octadecenoic acid and substrate or unchanged substrate.

\section{DISCUSSION}

From our results it is clear that the rumen bacteria are able to hydrogenate all but the $\Delta 14,17$-isomer of the complete series of methylene-interrupted cis,cis-octadecadienoic acids at least to the octadecenoic acid stage. Many isomers were hydrogenated to an extent similar to and, in the case of $\mathrm{P} 2 / 2, \mathrm{~T} 344$ and $\mathrm{R} 8 / 5$ with the $\Delta 4,7$-and $\Delta 5,8$-isomers, a greater extent than the usual substrate linoleic acid. Only the $\Delta 2,5$ - and $\Delta 9,12$-isomers appear to be conjugated before hydrogenation, which agrees with the work of Garcia et al. (1976); they did not examine the non-conjugated isomers as substrates for the hydrogenation system.

The $\Delta 12,15-$ and $\Delta 13,16$-isomers were only hydrogenated to octadecenoic acids even by group B bacteria, although this was not unexpected since bacteria T344, P 2/2 and probably bacterium $R 8 / 5$ are unable to hydrogenate octadecenoic acid with double bonds farther from the carboxyl group than C13 (Kemp et al. 1979, 1984). Even using mixed rumen micro-organisms we have not found $\Delta 15$-octadecenoic acid or its neighbouring isomers to be hydrogenated to stearic acid (Kemp et al. 1975). These results also suggest that whilst the $\Delta 10,13-$ and $\Delta 11,14$-isomers may suffer some non-specific attack, the $\Delta 12,15$ - and $\Delta 13,16$-isomers with $\mathrm{T} 344$ probably do not, because $\mathrm{T} 344$ can hydrogenate both cis- and trans-12-octadecenoic acid and cis-13-octadecenoic acid to stearic acid (Kemp et al. 1979). The two groups of bacteria do exhibit different bond specificities when hydrogenating trans,cis-11,15-octadecadienoic acid (Hazlewood et al. 1976). Group A bacteria attack the $\Delta 15$ bond and group $B$ the $\Delta 11$ bond to yield trans-11-octadecenoic acid and cis15-octadecenoic acid respectively (Kemp et al. 1975; Hazlewood et al. 1976). We found evidence for some trans-octadecenoic acids, but whether the isomerization occurs during or after production of the octadecenoic acid is not known, although we know that extensive cis-trans isomerization does occur when bacteria T344 and P $2 / 2$ are incubated with octadecenoic acids and that extensive bond migration can occur in the $\Delta 13-\Delta 16$ region of the fatty acid chain (Kemp \& Lander, 1984). Katz \& Keeney (1966) found a wide range of double-bond positions in the rumen octadecenoic acids, which most probably arose by bond migration since they were not found in the dietary fatty acids.

Although the precise reason for hydrogenation in the rumen is not clear, the possibility exists, and receives support from our growth results, that hydrogenation removes molecules which are potentially toxic to the hydrogenating bacteria and probably to other bacteria (Nieman, 1954) which would be important in the closely integrated rumen ecosystem. There would also be an advantage to the host ruminant where excessive levels of unsaturated fatty acids may cause myopathic conditions in the absence of adequate vitamin E (Blaxter, 1957). Only relatively small inhibitions of growth were found, but the levels of fatty acids used were low compared with those in the rumen, perhaps fifty times lower, even on a hay diet. In the rumen the effective concentration is probably reduced by adsorption of the fatty acids on to food particles. It is possible to increase the concentration of linoleic acid in our media at least fivefold whilst maintaining growth and hydrogenation of bacterium T344 by 
incorporating large quantities of starch, powdered grass or cellulose (P. Kemp and D. J. Lander, unpublished results).

With the evidence from the series of fatty acids reported here and the knowledge that cis- and trans-octadecenoic acids with double bonds nearer than $\mathrm{C} 13$ are hydrogenated (Kemp et al. 1984), we should be able to predict the fate of any unusual fatty acid given to ruminants. This is useful since any fatty acid not hydrogenated may find its way into ruminant milk, membrane and depot fats and so into the human diet.

\section{REFERENCES}

Blaxter, K. L. (1957). Veterinary Record 69, 1150-1155.

Christie, W. W. \& Holman, R. T. (1967). Chemistry and Physics of Lipids 1, 407-423.

Dawson, R. M. C. \& Kemp, P. (1970). In Physiology of Digestion and Metabolism in the Ruminant, pp. 504-518 [A. T. Phillipson, editor]. Newcastle upon Tyne: Oriel Press.

Garcia, P. T., Christie, W. W., Jenkin, H. M., Anderson, L. \& Holman, R. T. (1976). Biochimica et Biophysica Acta 424, 296-302.

Hazlewood, G. P. \& Dawson, R. M. C. (1975). Journal of General Microbiology 89, 163-174.

Hazlewood, G. P. \& Dawson, R. M. C. (1979). Journal of General Microbiology 112, 15-27.

Hazlewood, G. P., Kemp, P., Lander, D. J. \& Dawson, R. M. C. (1976). British Journal of Nutrition 35, $293-297$.

Hungate, R. E. (1969). In Methods in Microbiology, vol. 3B, pp. 117-132 [J. R. Norris and D. W. Ribbons, editors]. London: Academic Press.

Katz, I. \& Keeney, M. (1966). Journal of Dairy Science 49, 962-966.

Kemp, P. \& Lander, D. J. (1983). Biochemical Journal 216, 519-522.

Kemp, P. \& Lander, D. J. (1984). Journal of General Microbiology 130, 527-533.

Kemp, P., Lander, D. J. \& Gunstone, F. D. (1979). Abstracts 11th FEBS Meeting, Copenhagen. A5-1, 750.

Kemp, P., Lander, D. J. \& Gunstone, F. D. (1984). British Journal of Nutrition 52, 165-170.

Kemp, P., White, R. W. \& Lander, D. J. (1975). Journal of General Microbiology 90, 100-114.

Kepler, C. R. \& Tove, S. B. (1967). Journal of Biological Chemistry 242, 5686-5692.

Kepler, C. R., Tucker, W. P. \& Tove, S. B. (1971). Journal of Biological Chemistry 246, $2765-2771$.

Latham, M. J. \& Sharpe, E. M. (1971). In Isolation of Anaerobes, pp. 133-147 [D. A. Shapton and R. G. Board, editors]. London: Academic Press.

Nieman, C. (1954). Bacteriological Reviews 18, 147-167. 